\title{
Thrombosis revealing POEMS syndrome. About a case
}

\author{
Manifestations thrombotiques révélant un syndrome POEMS \\ A propos d'un cas
}

\author{
Cécile Dumas ${ }^{1}$ \\ François-Henri Bienvenu ${ }^{2}$ \\ James Hicks ${ }^{2}$ \\ Emmanuelle Weber ${ }^{2}$ \\ Pascal Sève ${ }^{2,3}$ \\ ${ }^{1}$ Service d'hématologie biologique, \\ Groupement hospitalier Nord, \\ Hôpital Croix-Rousse, Hospices \\ civils de Lyon, France \\ 2 Service de médecine interne, \\ Groupement hospitalier Nord, \\ Hôpital Croix-Rousse, Hospices \\ civils de Lyon, France \\ ${ }^{3}$ Université Claude Bernard Lyon 1, \\ Hesper EA 7425, Lyon, France
}

Article received December 20, 2019, accepted February 24, 2020

Correspondence: C. Dumas $<$ cecile.dumas@chu-lyon.fr>

\begin{abstract}
POEMS syndrome (polyneuropathy, organomegaly, endocrinopathy, monoclonal protein, skin changes) is a rare paraneoplastic disorder due to an underlying plasma cell dyscrasia. The diagnosis of POEMS syndrome requires a chronic polyneuropathy and a monoclonal lambda plasma cell-proliferative disorder (mandatory criteria), and various systematic symptoms such as sclerotic bone lesions, Castleman's disease, organomegaly, endocrinopathy, skin changes, papilloedema and biological abnormalities such as elevated vascular endothelial growth factor (VEGF), thrombocytosis or polycythaemia. We describe an observation of a patient with recurrent thrombosis with thrombocytosis that, after excluding a myeloproliferative neoplasm, proved to be due to POEMS syndrome. This case is unusual compared to the foreground thrombotic symptomatology. POEMS syndrome (polyneuropathy, organomegaly, endocrinopathy, monoclonal protein, skin changes) is a rare multi-systematic paraneoplastic disorder due to an underlying plasma cell disorder. The diagnosis of POEMS syndrome requires the presence of both mandatory criteria (a chronic polyneuropathy and a monoclonal plasma cell-proliferative disorder, always lambda restricted); at least one major (among sclerotic bone lesions, Castleman's disease, elevated VEGF (vascular endothelial growth factor)) and one minor criterion (among organomegaly, endocrinopathy, skin changes (haemangiomas, hypertrichosis, hyperpigmentation), papilloedema and thrombocytosis or polycythaemia. We describe an unusual observation of a young patient with recurrent thrombosis with thrombocytosis that, after excluding a myeloproliferative neoplasm, proved to be due to POEMS syndrome.
\end{abstract}

Key words: plasma cell disorder, POEMS syndrome, thrombosis

Résumé. Le syndrome POEMS (polyneuropathie, organomégalie, endocrinopathie, gammapathie monoclonale, lésions cutanées) est une maladie paranéoplasique rare liée à une dyscrasie plasmocytaire. Le diagnostic du syndrome POEMS associe une polyneuropathie chronique et une gammapathie monoclonale $\lambda$ (critères obligatoires), et des symptômes systémiques variés comme des lésions osseuses ostéocondensantes, une maladie de Castleman, une organomégalie, une endocrinopathie, des lésions cutanées, un œdème papillaire et des anomalies biologiques telles qu'une augmentation du facteur de croissance de l'endothélium vasculaire (VEGF), une thrombocytose ou une polyglobulie. Nous décrivons le cas d'un patient ayant présenté des thromboses récurrentes avec une thrombocytose qui, après élimination d'une néoplasie myéloproliférative, se sont avérées liées à un syndrome POEMS. Ce cas est inhabituel par rapport à la symptomatologie thrombotique au premier plan.

Mots clés : dyscrasie plasmocytaire, syndrome POEMS, thromboses 


\section{Current practice}

\section{The observation}

A 33-year-old male patient presented to the emergency room with complaints of persistent periumbilical pain. An abdominal contrast-enhanced computed tomography (CT) scan was performed, which revealed a medial infarction of the left adrenal gland (figure 1). Two years prior to admission, he presented with an ischemia of the left fifth toe with favorable outcomes under iloprost. He was treated long-term by antiplatelets aspirin and statine. Hematological evaluation revealed mild leukocytosis $(11.3 \mathrm{G} / \mathrm{L})$ with neutrophilia $(8.7 \mathrm{G} / \mathrm{L})$ and thrombocytosis $(679 \mathrm{G} / \mathrm{L})$ which had been detected on previous samples. Results of coagulation tests were normal including prothrombin time, partial thromboplastin time, fibrinogen, homocysteine, protein $\mathrm{C}$ and $\mathrm{S}$, antithrombin III, factor V Leiden and factor II G20210A mutations screen, as well as a search for antiphospholipid syndrome (absence of lupus anticoagulant, antiphospholipid antibodies). Two years prior to admission, a first bone marrow biopsy presented no argument for a myeloproliferative neoplasm and the search for BCR-ABL1 transcript and JAK2 V617F, CALR and MPL mutations was negative. Myeloproliferative neoplasm was excluded due to the absence of mutations by targeted highthroughput next-generation sequencing using a multigene panel in myeloid neoplasms. Serum protein electrophoresis revealed no hypergammaglobulinemia, whereas an $\operatorname{Ig} A \lambda$ monoclonal protein was detected by serum immunofixation electrophoresis (figure 2). Kappa (20 mg/L) and lambda $(32 \mathrm{mg} / \mathrm{L})$ light chain were discreetly increased, with a normal $\kappa / \lambda$ ratio $(0.64)$.

A new bone marrow aspiration and biopsy demonstrated $1-5 \%$ of plasma cells with flaming cytoplasm (figure 3).

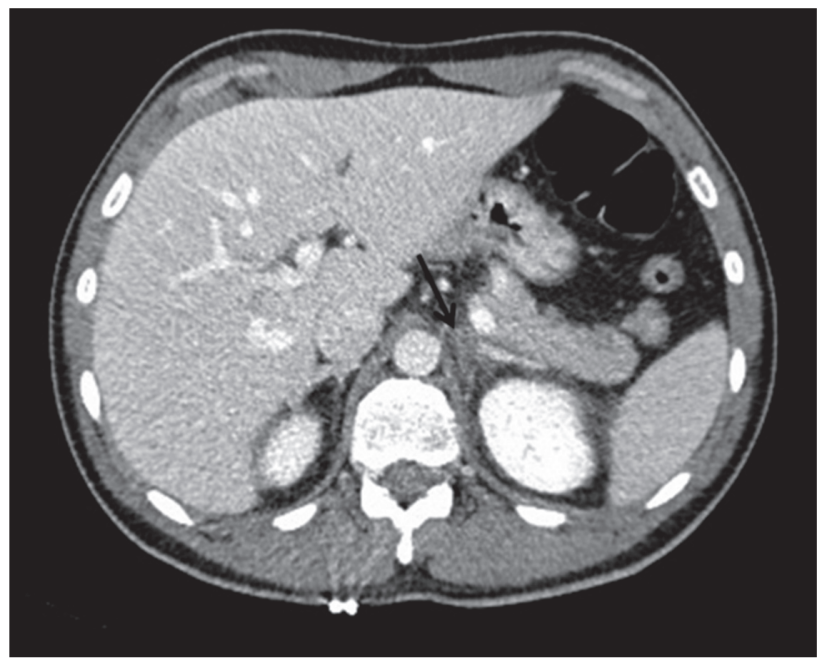

Figure 1. Abdominal contrast-enhanced computed tomography (portal venous phase) revealing left medial adrenal gland infarction (arrow).

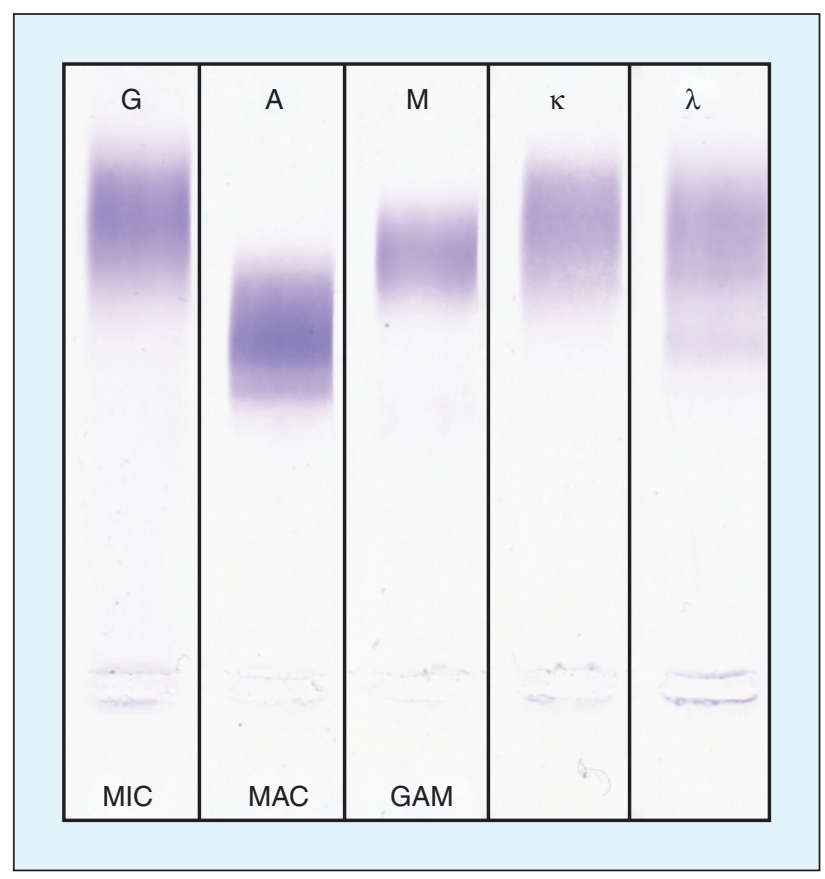

Figure 2. Serum immunofixation electrophoresis revealing the presence of a monoclonal $\lg A \lambda$ unquantifiable.

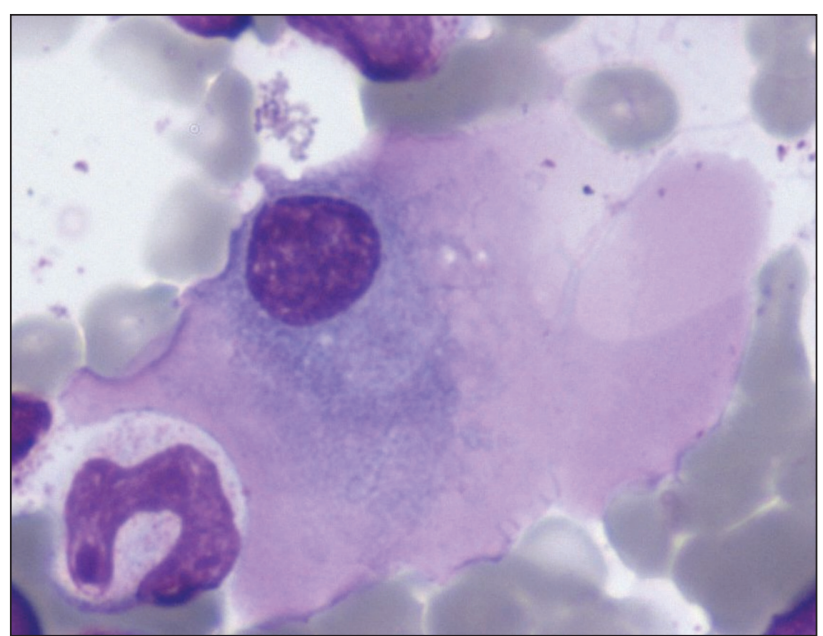

Figure 3. Image of plasma cell with flaming cytoplasm in bone marrow aspiration (x100 May-Grünwald-Giemsa stain).

$\mathrm{V} \beta$ repertoire sequencing from bone marrow plasma cells showed a restrictive usage of V $\lambda 1-44$ monoclonal immunoglobulin $\lambda$ light chain. This is one of the two types which usually characterizes POEMS syndrome, along with V $\lambda 140$ [1].

The serum VEGF was superior to $2000 \mathrm{pg} / \mathrm{mL}$ (reference range $60-710 \mathrm{pg} / \mathrm{mL}$ ). While the patient had an isolated patellar and Achilles areflexia, electromyography showed a sensory and motor demyelinating neuropathy with axonal degeneration. Bone scan did not reveal any osteolytic or 
Table 1. Criteria for the diagnosis of POEMS syndrome and their prevalence according to Dispenzieri.

Criteria for the diagnosis of POEMS syndrome

$(1+2)+($ one criteria required from 3 to 5$)+($ one criteria required from 6 to 11)

Major criteria

1. Polyneuropathy $(100 \%)$

2. Monoclonal plasma cell-proliferative disorder

(almost always $\lambda$ ) (100\%)

3. Castleman disease $(11-25 \%)$

4. Sclerotic bone lesions (95\%)

5. Vascular endothelial growth factor elevation
Minor criteria

6. Organomegaly (45-85\%) (splenomegaly, hepatomegaly or lymphoadenopathy)

7. Extravascular volume overload (29-87\%) (edema, pleural effusion, or ascites)

8. Endocrinopathy (67-84\%) (adrenal, thyroid, pituitary, gonadal, parathyroid, pancreatic)

9. Skin changes (68-89\%) (hyperpigmentation, hypertrichosis, glomeruloid hemangiomata, plethora, acrocyanosis, flushing, white nails)

10. Papilledema $(29-64 \%)$

11. Thrombocytosis (54-88\%) / polycythemia (12-19\%) osteosclerotic lesion. A diagnosis of POEMS syndrome was retained according to WHO 2016 criteria [2] (table 1). Treatment consisting of dexamethasone was started before autologous stem cell transplant [3] and the decrease of VEGF level was followed.

\section{Discussion}

POEMS syndrome is a rare multi-systematic disease associated with elevated VEGF secretion by plasma cell [4], which seems in part to be responsible for some of the symptoms, such as vascular permeability leading to nerve oedema, myelin damage and thereby inducing a rapidly developing neuropathy. However, its etiology and pathogenesis are not completely understood. POEMS diagnosis is based on clinical criteria and biological criteria (table 1). Cut-off for serum VEGF level to diagnosis POEMS syndrome is $1920 \mathrm{pg} / \mathrm{mL}$ (specificity 98\%, sensibility 73\%) [2] Our patient presented only the two mandatory criteria, VEGF elevation and thrombocytosis.

Bone marrow aspiration was a diagnostic help showing the presence of few abnormal plasma cell. Bone marrow infiltration by plasma cell is frequently under 5\% and exceptionally undetectable. Bone marrow biopsy is often necessary to demonstrate the infiltration. One-third of patients do not have clonal plasma cells on their iliac crest biopsy, These are the patient that present multiple solitary plasmacytomas [2].

To search monoclonal lambda restricted protein is the key to diagnosis. In most case, this monoclonal protein is revealed by immunofixation. Despite the fact that immunoglobulin lambda free light chains are elevated, the kappa/lambda ratio is usually normal [2].

High platelet count is seen in around half of POEMS patients. Arterial and venous thrombosis are less-common complications seen in nearly $20 \%$ cases [2]. These features may first lead towards the diagnosis of myeloproliferative disorders. Our report is of a patient with an adrenal infarction as an inaugural presentation of POEMS syndrome.
A prompt and accurate diagnosis is fundamental to initiate specific treatment, which can prevent worsening of neurological outcomes or severe visceral complications. POEMS patients with localized disease, defined as up to 3 discrete bone lesions and no evidence of clonal plasma cells on iliac crest biopsy are treated with localized radiotherapy, whereas chemotherapy (similar to that for multiple myeloma) is used in patients with diffuse disease to target tumoral cells [2].

\section{Conclusion}

Clinical presentation of POEMS syndrome is varied thus making diagnosis difficult. The diagnosis will be missed if it is not considered. Thrombotic events with high platelet count should be an alert in the absence of a myeloproliferative disorder and a search for lambda monoclonal components should be performed to consider a diagnosis of POEMS syndrome.

Acknowledgement. We wish to thank Pr Arnaud Jaccard and Sébastien Bender (Centre national de référence amylose AL et autres maladies par dépôt d'immunoglobulines monoclonales, CHU Limoges, France).

Conflict of interest: none of the authors has any conflict of interest to disclose concerning this article.

\section{References}

1. Abe D, Nakaseko C, Takeuchi M, Tanaka H, Ohwada C, Sakaida E, et al. Restrictive usage of monoclonal immunoglobulin lambda light chain germline in POEMS syndrome. Blood 2008; 112(3) : 836-9.

2. Dispenzieri A. POEMS Syndrome: 2019 Update on diagnosis, riskstratification and management. Am J Hematol 2019; 94(7) : 812-27.

3. Karam C, Klein CJ, Dispenzieri A, Dyck PJ, Mandrekar J, D’Souza A, et al. Polyneuropathy improvement following autologous stem cell transplantation for POEMS syndrome. Neurology 2015 ; 84(19) : 1981-7.

4. Wang C, Huang XF, Cai QQ, Cao XX, Cai H, Zhou D, et al. Remarkable expression of vascular endothelial growth factor in bone marrow plasma cells of patients with POEMS syndrome. Leuk Res 2016; 50 : 78-84. 